\title{
Review Article \\ Obesity Reduces Cognitive and Motor Functions across the Lifespan
}

\author{
Chuanming Wang, ${ }^{1}$ John S. Y. Chan, ${ }^{2,3}$ Lijie Ren, ${ }^{4}$ and Jin H. Yan ${ }^{2}$ \\ ${ }^{1}$ Department of Neurology, The Affiliated Shenzhen Nanshan Hospital, Shenzhen University, Shenzhen 518000, China \\ ${ }^{2}$ Center for Brain Disorders and Cognitive Neuroscience, Shenzhen University, Shenzhen 518060, China \\ ${ }^{3}$ Department of Psychology, The Chinese University of Hong Kong, Shatin, Hong Kong \\ ${ }^{4}$ Department of Neurology, Shenzhen Second People's Hospital, Shenzhen University, Shenzhen 518035, China
}

Correspondence should be addressed to Jin H. Yan; jhyan@sfsu.edu

Received 21 July 2015; Accepted 15 October 2015

Academic Editor: Mauricio Arcos-Burgos

Copyright (C) 2016 Chuanming Wang et al. This is an open access article distributed under the Creative Commons Attribution License, which permits unrestricted use, distribution, and reproduction in any medium, provided the original work is properly cited.

Due to a sedentary lifestyle, more and more people are becoming obese nowadays. In addition to health-related problems, obesity can also impair cognition and motor performance. Previous results have shown that obesity mainly affects cognition and motor behaviors through altering brain functions and musculoskeletal system, respectively. Many factors, such as insulin/leptin dysregulation and inflammation, mediate the effect of obesity and cognition and motor behaviors. Substantial evidence has suggested exercise to be an effective way to improve obesity and related cognitive and motor dysfunctions. This paper aims to discuss the association of obesity with cognition and motor behaviors and its underlying mechanisms. Following this, mechanisms of exercise to improve obesity-related dysfunctions are described. Finally, implications and future research direction are raised.

\section{Introduction}

Obesity is the overaccumulation of fat which has aversive effects on health. The World Health Organization (WHO) defines overweight and obesity as body mass index (BMI) $\geq 25$ and $\mathrm{BMI} \geq 30$, respectively [1]. Around the world, obesity has become a worrying health and social issue, threatening lives of thousands of people. According to the WHO [1], over 1.9 billion adults (39\% adults) were overweight among which more than 600 million (13\% adults) were obese. Childhood obesity is also common that 42 million children were overweight or obese in 2013 [1]. Considering its high prevalence, it is pressing to study the pathogenesis, manifestations, and prevention of obesity.

Obesity is related to a range of health-related problems, such as diabetes, heart disease, hypertension, and cancer [2]. Compared to normal-weight individuals, obese individuals have a reduced life expectancy [3]. Obese children show greater cardiovascular risk factors and persistence of obesity into their adulthood, which may be associated with higher likelihood of premature mortality $[4,5]$. In addition to health problems, obesity is associated with poorer cognition and motor control, and altered brain plasticity. In this review, we first look into the behavioral manifestations of obese individuals' cognition and motor control capabilities. Next, obesity-related changes in brain plasticity will be discussed. Following this, the effects of physical exercise to combat obesity and obesity-related deficits in cognition and motor control will also be described. Finally, implications and future research directions are raised.

\section{Cognition}

Overweight and obesity are usually related to poorer cognition across lifespan [6-8]; however, the association between BMI and cognitive function is weaker in old age $[9,10]$, partly due to inaccurate adiposity measurement in the aged people [11]. Indirect evidence has shown an association between western high fat diet and impaired cognitive functions [12]. Based on BMI data, individuals who are overweight or obese 
fall in the lowest quartile of global cognition, verbal fluency, delayed recall, immediate logical memory, and intelligence [13].

Other than BMI, other adiposity measures are also related to cognitive performance and brain changes. Visceral adiposity is inversely correlated with verbal memory and attention. High visceral adiposity is associated with smaller hippocampus and larger ventricular volume [14]. There is also a negative correlation between waist-to-hip ratio and hippocampal volume and a positive correlation between waistto-hip ratio and white matter hyperintensities [15]. Compared to BMI, central adiposity has a stronger association with the risk of developing cognitive impairment and dementia in women [16]. Hence, studies using BMI as the only indicator of obesity may not be sensitive enough to capture obesityinduced cognitive dysfunctions.

Neuroimaging studies demonstrate atrophy in the frontal lobes, anterior cingulate gyrus, hippocampus, and thalamus in older obese individuals [17]. BMI increase is associated with lower metabolic activity in the prefrontal cortex and cingulate gyrus, smaller gray matter volume in many brain regions (particularly prefrontal cortex), and deficient white matter integrity in the uncinated fasciculus which is a structure connecting the frontal and temporal lobes [18-22]. Smaller gray matter volume in the left orbitofrontal region is related to poorer executive performance in obese women [21].

Childhood obesity is related to the reduced executive function, attention, mental rotation, mathematics, and reading achievement [23-25]. Obese adolescents have deficits in a range of cognitive functions, such as attention and executive functions $[26,27]$. An animal study shows that high fat diet induces similar morphometric and metabolic changes in juvenile and adult mice; however, only early exposure to high fat diet hurts relational memory flexibility and decreases neurogenesis [28]. Thus, early exposure to high fat diet may be particularly deleterious to cognition.

People with higher midlife BMI have lower global cognition than their thinner counterparts [29] and midlife obesity is related to the accelerated cognitive aging, but this association is weaker in older adulthood [30]. Both age and BMI contribute independently to decreased brain volume in middle and older adulthood [31]. It is more likely for an older adult to have lower cognitive abilities if he/she was overweight or obese during middle age $[32,33]$. Midlife obesity is related to an increased pace of deterioration in executive functions and an increase in waist-to-hip ratio is associated with substantial reduction in total brain volume [34]. Lower BMI and waist circumference and higher fat-free mass are associated with slower cognitive decline [35]. Midlife overweight/obesity, particularly with metabolic abnormality, is associated with higher dementia risk in older adulthood [33, 36-40]. Moreover, high midlife BMI is related to neuron and myelin abnormalities [41]. Hence, midlife is a critical period in which the overweight/obese status can predict one's cognitive functions and brain health in later life [42].

\section{Motor Control}

Besides cognition, obesity also affects motor control capabilities, degrading daily functions and health [43]. Children who are obese or overweight are poorer in gross and fine motor control and have delayed motor development [4450]. Obese boys have poorer motor skills and a reduced activity of daily living [51]. Obese girls of 6th and 7th grades participate in less physical activity and have lower enjoyment of physical activity [52]. Children with high BMI have lower level of run which is a fundamental motor skill based on which complex motor skills are learned [53]. Cliff et al. [54] observe that the prevalence of mastery of all fundamental motor skills is lower in overweight/obese children, especially for run, slide, hop, dribble, and kick. In addition to BMI, waist circumference is also related to children's and adolescents' ability to perform fundamental motor skills [55]. There is an inverse relationship of BMI with fine motor precision, balance, running speed and agility, and strength in the 1st graders [56]. Obese children also have difficulty in postural coordination and a heightened dependency on vision during locomotion which is rather automatic in nonobese children $[57,58]$.

Adiposity is related to muscle quality ratio that is associated with motor conduction velocity and finger tapping speed [59]. Obesity is related to greater fluctuation in handgrip force production [60]. Subcutaneous fatness can account for a significant variance of health-related and motor fitness [61]. Excessive fat mass is associated with poorer posture and walking [62]. In middle and older adults, a combination of high BMI (or waist circumference) and high blood pressure is related to lower motor speed and manual dexterity [63]. During postural control, obese individuals require greater attention resources to maintain balance during unipedal stance [64]; this implicates that obese people consume attention resources to compensate for their motor deficits.

\section{Obesity-Related Changes in Brain Plasticity}

A number of factors may mediate obesity's effects on cognition and motor behaviors. For example, obesity may affect brain structure, leptin and insulin dysregulation, oxidative stress, cerebrovascular function, blood-brain barrier, and inflammation [11, 65-71]. Some also suggest that obesityrelated changes in metabolism interact with age to impair brain functions [72].

In terms of brain structure, obese individuals have lower cortical thickness in the left superior frontal and right medial orbitofrontal cortex. The volumes of ventral diencephalon and brainstem are also reduced in obese people [73]. There is also a negative relationship between neuronal injury and gray matter density in hippocampus and cerebellum in overweight and obese individuals [74]. It is suggested that the medial orbitofrontal cortex, hippocampus, and cerebellum are involved in reward-based learning, memory, and motor control and learning [75-77]; structural alterations in these regions may be associated with deficits in cognitive and motor domains. Hitherto, the mechanisms underlying obesity's effects on brain structure are not clear. 
High fat diet increases oxidative stress and inflammatory signaling in the brain [78]. Diet-induced obesity promotes reactive oxygen species in the brain which is associated with both body weight and adiposity $[79,80]$. In children, intake of saturated fatty acids impairs both relational and item memory [81]. Occurrence of 15-week obesity during childhood can induce permanent epigenetic changes in rat's brain [82]. In rats, triglycerides diminish the passage of insulin-like growth factors (IGFs) into the brain through cerebrospinal fluid, impair hippocampal long-term potentiation, and impede leptin transportation across the blood-brain barrier [83-85]. Juvenile exposure to high fat diet impairs long-term spatial memory, but not short-term memory, suggesting a selective impairment of consolidation which is likely contributed by increased proinflammatory cytokine expression in the hippocampus [86]. Moreover, consumption of western diet is thought to degrade blood-brain barrier, which consequently damages hippocampus and leads to dementia [87]. Relative to those having normal diet, mice consuming high fat diet for 17 days develop insulin resistance in cerebral cortex tissues, degraded synaptic integrity, and poorer spatial memory [88].

Leptin is a cytokine and satiety hormone helping regulate appetite and energy expenditure. It can cross the bloodbrain barrier and binds to presynaptic GABAergic neurons to produce its effects $[89,90]$. Leptin production is increased in obesity [91]. As leptin receptors are widespread in the brain (e.g., throughout the cortex and the hippocampus), leptin can modulate memory processes [92]. Obese mice with impaired leptin signaling have deficits of hippocampal-dependent memory [93] and increased basal hippocampal inflammation $[94,95]$. Leptin is related to neurogenesis, axonal growth, and synaptogenesis in addition to hypothalamic functions [9698]. For hippocampal neurons, leptin plays a role in longterm potentiation and depression and thus is important for synaptic plasticity $[92,99,100]$. Compared to those with low leptin level, the elderly with high leptin level show less cognitive decline during aging [101]. High leptin level in individuals with small waist circumference is related to less cognitive decline over 10 years [102]. The presence of leptin may decrease the production of amyloid and speed up the removal of $\beta$-amyloid [103]. Older adults with higher leptin level are at a lower risk of developing dementia [104]. Obese individuals usually develop leptin resistance [105] which results in an increase in food intake and alteration of energy expenditure [90].

The circulating levels of insulin and signaling pathway are altered in obesity; this interacts with inflammatory processes to modulate cognition and behaviors [106]. Insulin plays a role in modulating hippocampal synaptic plasticity [107]. As insulin receptors are widespread in hippocampal and cortical brain structures, insulin signaling can contribute to the formation of declarative memory [108]. Insulin concentrations vary with adiposity and there is a negative relationship between the amount of visceral fat and insulin sensitivity [109]. Insulin resistance can result from high fat consumption or obesity [110, 111]. Dysfunctional insulin signaling can induce inflammation and promote $\beta$-amyloid and tau pathology, contributing to neurodegeneration [112, 113]. Insulin resistance can mediate cognitive impairment and neurodegeneration as insulin and IGFs can regulate neuronal survival, metabolism, and brain plasticity [114, 115]. During insulin resistance, there is a failure of cells to metabolize glucose, which consequently triggers an increase of insulin level. Insulin signaling is related to tau phosphorylation, an early pathology of Alzheimer's disease [116, 117]; this is complementary to the fact that there are a large number of insulin-sensitive glucose transporters in the medial temporal lobe [118]. Thus, insulin dysregulation in the obese people likely confers a greater risk of dementia to them.

The adipose tissue produces many substances for metabolism (adipokines, such as BDNF) and inflammation (cytokines, such as leptin). Many cytokines, such as interleukin-1, produced by the adipose tissue can cross the blood-brain barrier and affect cognitive functions through neuroinflammation [95, 119]. Adiponectin is involved in regulating glucose level and fatty acid breakdown. Similar to leptin, it exerts its effects in the brain to bring about weight reduction [120]. Its level is negatively associated with adiposity and can protect hippocampal cells [119]. Reduced hippocampal adiponectin levels are observed in aging animals, independent of high fat diet intake [121]. Thus, adiponectin is important for neurodegeneration prevention.

Neurotrophins, such as IGF-1 and BDNF, can mediate obesity's effects on cognition and behaviors. IGF-1 is mainly produced in liver and binds to the IGF-1 or insulin receptors to exert its effects to stimulate cell growth and proliferation and promote $\beta$-amyloid clearance in the brain [122]. Obese individuals usually show IGF-1 resistance, degrading their capability to prevent $\beta$-amyloid deposition and neurodegeneration $[114,123]$. Besides, BDNF can bind to many receptors, such as TrkB and LNGF receptors, to support neuronal survival and stimulate neurogenesis and synaptogenesis [124126]. Cardiometabolic diseases are usually associated with low BDNF [127]. BDNF promotes neuronal differentiation and survival, neurogenesis, and brain plasticity and is thus particularly crucial for learning and memory [128]. High fat diet reduces BDNF level in the hippocampus [129], and the impaired hippocampal synaptic plasticity and cognition are possibly through BDNF's effects on dendritic spines [130]. Diet-induced obesity reduces hippocampal expression of BDNF and presynaptic synaptophysin, which are related to an impairment of spatial learning in mice [131].

Although mounting evidence shows that obesity is associated with structural and functional brain changes, the causal link between them requires further investigations. In contrast, the causal link between diet and brain changes is much clearer. The composition of gut microbiota appears to be causally related to obesity [132-134], playing a significant role in body weigh regulation since birth $[135,136]$. Gut microbiota plays a key role in childhood obesity and brain development $[137,138]$. A comparison of germ-free mice and conventionally reared mice has demonstrated that germfree mice are leaner and more resistant to diet-induced obesity [139]. Obese and nonobese individuals have different diversity and composition of gut microbiota [140, 141]. As gut microbiota controls energy extraction and storage in the body, significant changes in gut microbiota can result in obesity and insulin resistance [139, 140, 142]. 
It has been suggested that diet can influence gut microbiota which in turn impacts the brain and behaviors through neural, hormonal, immune, and metabolic pathways [143, 144]. Transplantation of gut microbiota of diet-induced obese mice to lean mice is sufficient to bring about neurobehavioral changes through increasing neuroinflammation and disrupting cerebrovascular homeostasis $[145,146]$. Mice consuming high energy diet containing higher percentage of Clostridiales and lower expression of Bacteroidales have poorer cognitive flexibility [147]. In humans, the Firmicutes/Bacteroidetes ratio is positively associated with BMI [148]. Gut microbiota can modulate a range of neurotrophins, such as BDNF and synaptophysin, to affect neural plasticity $[149,150]$. Thus, diet changes gut microbiota which influences neurophysiology and neurotrophins, eventually impacting cognition and behaviors.

Previous results have shown that obesity-related brain plasticity alteration is a multifaceted issue, which can inflict permanent harm to individuals in their early ages. Thus, it would be optimal to combat obesity during childhood.

\section{Exercise Improves Brain Functions}

Exercise can improve physical and cognitive performance, and quality of life in the elderly [151-155]. In humans, those who are highly fit or aerobically trained have greater prefrontal and parietal activations for spatial selection and inhibitory functioning [156]. There is a positive relationship between aerobic fitness and spatial memory which is mediated by hippocampus volume [157]. Aerobic training can increase hippocampal volume of the elderly (with or without mild cognitive impairment) and increases plasma BDNF level in both patients of Alzheimer's disease and healthy controls [158-163]. Regular physical activity is related to better cognition, less cognitive decline, and a lower risk of developing dementia $[164,165]$. As young as children, aerobic fitness can predict cognitive performance over time [166]. Besides cognition, higher level of physical activity is related to a reduced white matter hyperintensity burden on motor function in the aged people [167]. BDNF concentration is associated with retention performance of motor skill after learning [168]. Lifelong exercise can preserve white matter microstructure related to motor control and coordination in the elderly [169]. In addition, regular physical activity has long been suggested to be an effective way to improve obesity and related problems [170, 171]. Exercising 5 days per week for 15 weeks can improve executive functions in overweight children [172]. High-intensity physical activity (both aerobic and endurance training) for 4 months improves cognition and oxygen extraction in obese individuals [173].

The effectiveness of exercise may be moderated by exercise intensity and duration, and exerciser's developmental stage $[174,175]$. Exercise intensity can be related both to behavioral outcomes and to changes in brain structure and BDNF level. High dose group improves planning more than the low dose group [172]. Greater amount of physical activity in early life is associated with larger prefrontal and hippocampal volumes [176]. Individuals receiving lowintensity exercise, but not high-intensity, show increased BDNF expression [177]. BDNF level depends on exercise intensity [178]; some observe that moderate-intensity exercise is the most effective to promote BDNF in the elderly [179]. Thus, it seems that a moderate intensity of exercise is optimal. In addition to exercise intensity, duration of exercise is also crucial. Tomporowski et al. [180] fail to observe any augmentation of task switching performance after a single bout of moderately intense exercise. In midlife mice, only 4-month (but not 2-month) running training can trigger activation of the antiamyloidogenic, prosurvival, synaptogenic, and neuroprotective pathways [181]. Wheel running for 14 days can increase cell proliferation in the dentate gyrus whereas wheel running for 56 days can additionally facilitate long-term potentiation in this region [182]. These show that a longer duration of exercise favors changes in the brains. Moreover, the developmental stage of exerciser is associated with benefits of exercise. Four-week exercise can improve recognition memory in adult rats, but no such enhancement can be recorded 2 weeks after cessation of training. However, in adolescent rats, the enhancement of recognition memory is preserved [183]. These nicely demonstrate that younger animals benefit more from exercise.

At the neuronal level, physical activity can enhance neurogenesis, neuroadaptation, and neuroprotection though the actions of neurotrophic factors [184-190]. Hippocampal function is restored by physical activity through enhancing the expression of neurotrophic factors to promote neurogenesis, angiogenesis, and synaptic plasticity [191-193]. For example, BDNF level increases with physical activity, particularly regular exercise $[194,195]$. It is found that BDNF can stimulate DNA repair to protect cortical neurons against oxidative stress [196]. Short bout of mild exercise for 5 weeks improves both oxygen consumption and long-term spatial learning and memory in aged rats which is associated with hippocampal BDNF level [197]. Following physical activity, hippocampal BDNF level and TrkB receptor activation are increased [198]. The elevated BDNF level in the dentate gyrus is sufficient to induce spatial memory improvement [199]. A week of voluntary exercise is sufficient to increase the activity of tissue type plasminogen activator to facilitate the cleavage of proBDNF into mBNDF [200]. Also, exercise promotes sirtuin 1, stimulates mitochondrial biogenesis, and prevents neurodegeneration [201].

Exercise can be related to structural brain changes [202]. A 7-day exercise intervention can increase gray matter volumes in the motor, somatosensory, association, and visual cortices in rats [203]. Exercising for 6 months reduces default mode network activity in the precuneus [204] while one-year walking increases functional connectivity within the default mode network and frontal executive network [205]. Regular physical activity can reduce proinflammatory and increase anti-inflammatory signaling and reduce oxidative stress in aged animals [206, 207]. Exercise also reduces peripheral risk factors, such as diabetes and cardiovascular diseases which are associated with neurodegeneration [208]. Furthermore, vasculature is altered after exercise. In middle-aged rats, total length and surface area of cortical capillaries are increased 


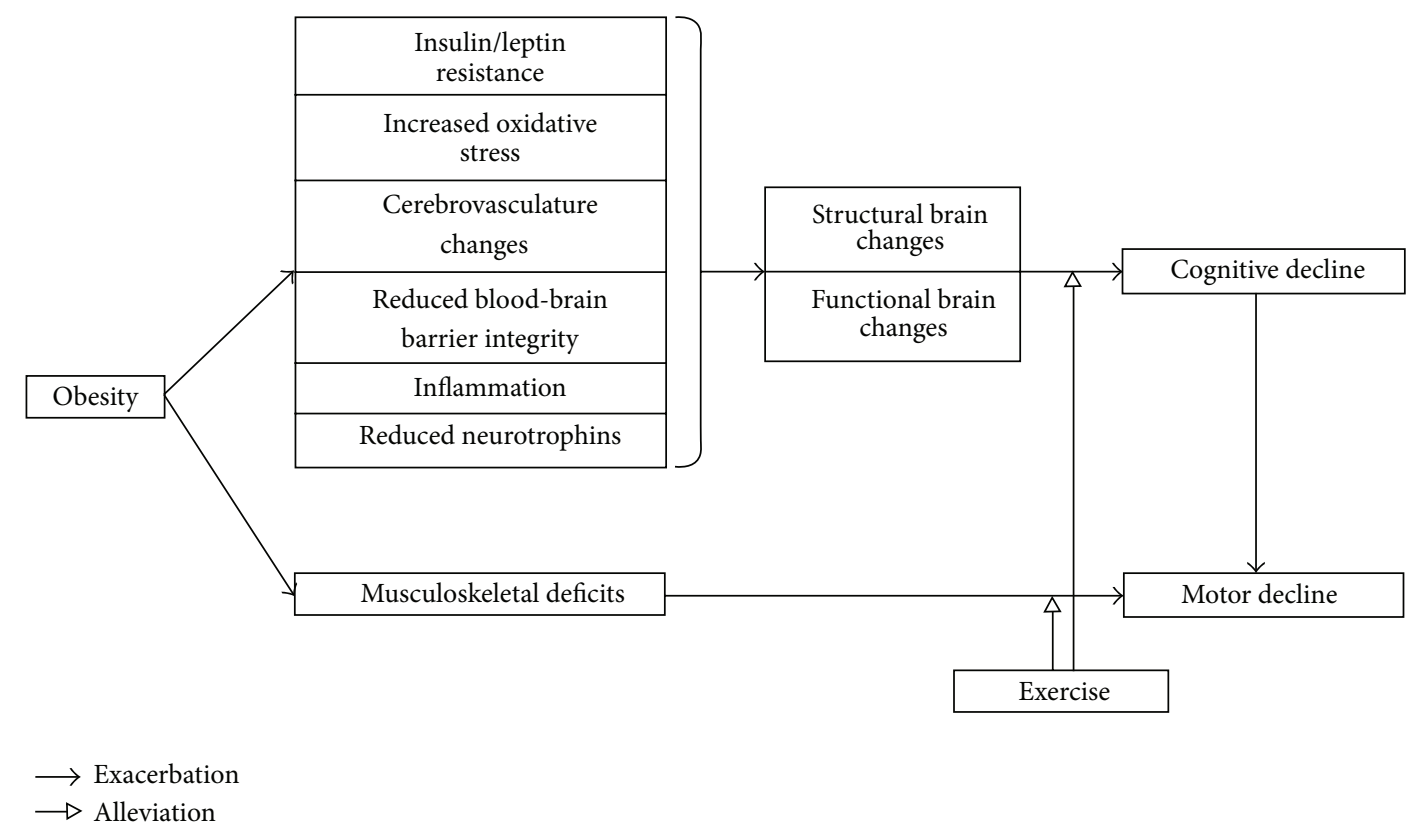

FIGURE 1: Factors mediating the effects of obesity and exercise on cognition and motor behaviors. Obesity affects cognition mainly through brain changes and influences motor behaviors through degrading the musculoskeletal system. Exercise can alleviate the deleterious effects of the obesity-related mediators on cognition and motor performance.

after running [209]. Aerobic exercise at midlife can improve vascular dysfunctions, astrocyte hypertrophy, and myelin dysregulation associated with sedentary lifestyle [210, 211].

Exercise is associated with a range of improvements in the brain through a range of mechanisms in individuals of different weight statuses (Figure 1). The effectiveness of exercise depends on the training parameters, such as intensity, duration, and developmental stage of exerciser. Previous research results have consistently suggested that moderately intense exercise for a long enough period of time is especially beneficial for young exercisers.

\section{Implications and Future Research}

More and more people are becoming obese, producing aversive effects on their cognition, motor behaviors, and quality of life [1]. Previous research has suggested that altered brain structure and activation mediate obesity's influences on cognition [17-21], whereas obesity influences the musculoskeletal system to degrade motor performance [59]. As motor performance partly depends on cognitive ability [64], obesity may indirectly contribute to motor deficits through cognitive decline (Figure 1).

Substantial research has shown that obesity affects our cognition and motor behaviors through different mechanisms, possibly through altering brain structure, leptin/insulin regulation, oxidative stress, cerebrovascular function, blood-brain barrier, and inflammation [11, 65-71]. The validity of these proposed mechanisms requires further examinations.

Regular physical activity benefits both cognition and motor behaviors. It is suggested that moderately intense exercise for a long enough period of time seems favorable; however, the training parameter for optimal outcomes remains to be determined. Most of the previous research focuses on aerobic exercise; the efficacy of anaerobic exercise to improve obesity and related dysfunctions is not well understood. More efforts should be devoted to investigate the efficacy of anaerobic exercise, in comparison with aerobic exercise. Moreover, starting exercising in young age is particularly important to protect from neurodegeneration in old age. As childhood obesity is becoming more prevalent [2325], introducing physical activity intervention in childhood may help children improve obesity and prevent age-related functional decline in old age.

In addition to exercise, leptin replacement therapy, inhaled insulin therapy, and caloric restriction have also been proposed to improve obesity. Leptin is responsible for energy balance and body weight and can affect neurogenesis and brain functions [212]. It enhances immune response and regulates inflammation [212]. It is observed that 18month leptin replacement therapy increases gray matter concentration and activations in brain regions implicated in hunger and satiation neural circuits [213, 214]. During weight loss, leptin is reduced, facilitating food intake. Leptin therapy helps sustain weight loss [215].

There are insulin disturbances in obese individuals [216, 217]. Insulin resistance plays an important role in obesity and cognitive impairments [218]. It is found that intranasal insulin exerts anorexic effects, promoting satiety and regulating food intake $[219,220]$. Inhaled insulin reaches the brain through olfactory nerves and specific receptors in bloodbrain barrier to exert its effects [221]. Caloric restriction also improves obesity and reverses deficits in leptin receptor 
protein and signaling associated with diet-induced obesity [222]. After 3 months of caloric restriction, serum BDNF increases in overweight and obese individuals [223]. Dietinduced weight loss is related to a decrease in plasma free fatty acid and improvement in episodic memory [224]. Hitherto, the efficacy of leptin replacement therapy, inhaled insulin therapy, and caloric restriction on cognition and motor behaviors is poorly understood, which warrants further verification.

\section{Conclusions}

Obesity has become a worrying health and social issue. It affects cognition mainly through altering the brain structures and functions [17-21], and motor performance through degrading musculoskeletal system [59]. Obesity can affect brain structure, leptin/insulin dysregulation, oxidative stress, cerebrovascular function, blood-brain barrier, and inflammation [11, 65-71], which are involved in the deterioration of cognitive and motor functions. A host of previous research has suggested that exercise can improve both obesity-related cognitive and motor declines. As more and more people develop obesity in young age, introducing exercise intervention early would result in the greatest benefits.

\section{Disclosure}

Chuanming Wang and John S. Y. Chan are co-first authors.

\section{Conflict of Interests}

The authors have no conflict of interests to declare.

\section{Acknowledgments}

This research was supported by the Natural Science Foundation of SZU (to Jin H. Yan) and in part by a grant from the Neuro-Academics Hong Kong (to John S. Y. Chan).

\section{References}

[1] Organization WHO, "Obesity and overweight," World Health Organization, http://www.who.int/mediacentre/factsheets/fs311/ en/.

[2] G. A. Bray, "Medical consequences of obesity," Journal of Clinical Endocrinology and Metabolism, vol. 89, no. 6, pp. 2583-2589, 2004.

[3] A. Peeters, J. J. Barendregt, F. Willekens et al., "Obesity in adulthood and its consequences for life expectancy: a life-table analysis," Annals of Internal Medicine, vol. 138, no. 1, pp. 24-32, 2003.

[4] J. J. Reilly, E. Methven, Z. C. McDowell et al., "Health consequences of obesity," Archives of Disease in Childhood, vol. 88, no. 9, pp. 748-752, 2003.

[5] A. Must and R. S. Strauss, "Risks and consequences of childhood and adolescent obesity," International Journal of Obesity and Related Metabolic Disorders, vol. 23, supplement 2, pp. S2-S11, 1999.
[6] C. Prickett, L. Brennan, and R. Stolwyk, "Examining the relationship between obesity and cognitive function: a systematic literature review," Obesity Research and Clinical Practice, vol. 9, no. 2, pp. 93-113, 2015.

[7] J. Gunstad, A. Lhotsky, C. R. Wendell, L. Ferrucci, and A. B. Zonderman, "Longitudinal examination of obesity and cognitive function: results from the baltimore longitudinal study of aging," Neuroepidemiology, vol. 34, no. 4, pp. 222-229, 2010.

[8] S. Sabia, M. Kivimaki, M. J. Shipley, M. G. Marmot, and A. Singh-Manoux, "Body mass index over the adult life course and cognition in late midlife: the Whitehall II Cohort study," American Journal of Clinical Nutrition, vol. 89, no. 2, pp. 601607, 2009.

[9] A. K. Dahl Aslan, J. M. Starr, A. Pattie, and I. Deary, “Cognitive consequences of overweight and obesity in the ninth decade of life?" Age and Ageing, vol. 44, no. 1, pp. 59-65, 2015.

[10] D. H. Yoon, S. H. Choi, J. H. Yu, J. H. Ha, S. H. Ryu, and D. H. Park, "The relationship between visceral adiposity and cognitive performance in older adults," Age and Ageing, vol. 41, no. 4, pp. 456-461, 2012.

[11] E. Smith, P. Hay, L. Campbell, and J. N. Trollor, "A review of the association between obesity and cognitive function across the lifespan: implications for novel approaches to prevention and treatment," Obesity Reviews, vol. 12, no. 9, pp. 740-755, 2011.

[12] H. Francis and R. Stevenson, "The longer-term impacts of Western diet on human cognition and the brain," Appetite, vol. 63, pp. 119-128, 2013.

[13] J. Benito-León, A. J. Mitchell, J. Hernández-Gallego, and F. Bermejo-Pareja, "Obesity and impaired cognitive functioning in the elderly: a population-based cross-sectional study (NEDICES)," European Journal of Neurology, vol. 20, no. 6, p. 899-e77, 2013.

[14] V. Isaac, S. Sim, H. Zheng, V. Zagorodnov, E. Shyong Tai, and M. Chee, "Adverse associations between visceral adiposity, brain structure, and cognitive performance in healthy elderly," Frontiers in Aging Neuroscience, vol. 3, article 12, 2011.

[15] W. Jagust, D. Harvey, D. Mungas, and M. Haan, "Central obesity and the aging brain," Archives of Neurology, vol. 62, no. 10, pp. 1545-1548, 2005.

[16] D. R. Kerwin, S. A. Gaussoin, R. T. Chlebowski et al., "Interaction between body mass index and central adiposity and risk of incident cognitive impairment and dementia: results from the women's health initiative memory study," Journal of the American Geriatrics Society, vol. 59, no. 1, pp. 107-112, 2011.

[17] C. A. Raji, A. J. Ho, N. N. Parikshak et al., "Brain structure and obesity," Human Brain Mapping, vol. 31, no. 3, pp. 353-364, 2010.

[18] J. D. Bolzenius, D. H. Laidlaw, R. P. Cabeen et al., "Brain structure and cognitive correlates of body mass index in healthy older adults," Behavioural Brain Research, vol. 278, pp. 342-347, 2015.

[19] Y. Taki, S. Kinomura, K. Sato et al., "Relationship between body mass index and gray matter volume in 1,428 healthy individuals," Obesity, vol. 16, no. 1, pp. 119-124, 2008.

[20] N. D. Volkow, G.-J. Wang, F. Telang et al., "Inverse association between BMI and prefrontal metabolic activity in healthy adults," Obesity, vol. 17, no. 1, pp. 60-65, 2009.

[21] K. Walther, A. C. Birdsill, E. L. Glisky, and L. Ryan, "Structural brain differences and cognitive functioning related to body mass index in older females," Human Brain Mapping, vol. 31, no. 7, pp. 1052-1064, 2010. 
[22] A. A. Willette and D. Kapogiannis, "Does the brain shrink as the waist expands?" Ageing Research Reviews, vol. 20, pp. 86-97, 2015.

[23] C. L. Davis and S. Cooper, "Fitness, fatness, cognition, behavior, and academic achievement among overweight children: do cross-sectional associations correspond to exercise trial outcomes?” Preventive Medicine, vol. 52, pp. S65-S69, 2011.

[24] R. Cserjési, D. Molnár, O. Luminet, and L. Lénárd, "Is there any relationship between obesity and mental flexibility in children?" Appetite, vol. 49, no. 3, pp. 675-678, 2007.

[25] P. Jansen, A. Schmelter, L. Kasten, and M. Heil, "Impaired mental rotation performance in overweight children," Appetite, vol. 56, no. 3, pp. 766-769, 2011.

[26] K. L. Lokken, A. G. Boeka, H. M. Austin, J. Gunstad, and C. M. Harmon, "Evidence of executive dysfunction in extremely obese adolescents: a pilot study," Surgery for Obesity and Related Diseases, vol. 5, no. 5, pp. 547-552, 2009.

[27] D. H. Schwartz, G. Leonard, M. Perron et al., "Visceral fat is associated with lower executive functioning in adolescents," International Journal of Obesity, vol. 37, no. 10, pp. 1336-1343, 2013.

[28] C. Boitard, N. Etchamendy, J. Sauvant et al., "Juvenile, but not adult exposure to high-fat diet impairs relational memory and hippocampal neurogenesis in mice," Hippocampus, vol. 22, no. 11, pp. 2095-2100, 2012.

[29] A. Dahl, L. B. Hassing, E. Fransson et al., "Being overweight in midlife is associated with lower cognitive ability and steeper cognitive decline in late life," Journals of Gerontology-Series A: Biological Sciences and Medical Sciences, vol. 65, no. 1, pp. 57-62, 2010.

[30] A. K. Dahl and L. B. Hassing, "Obesity and cognitive aging," Epidemiologic Reviews, vol. 35, no. 1, pp. 22-32, 2013.

[31] M. A. Ward, C. M. Carlsson, M. A. Trivedi, M. A. Sager, and S. C. Johnson, "The effect of body mass index on global brain volume in middle-aged adults: a cross sectional study," BMC Neurology, vol. 5, article 23, 2005.

[32] A. K. Dahl, L. B. Hassing, E. I. Fransson, M. Gatz, C. A. Reynolds, and N. L. Pedersen, "Body mass index across midlife and cognitive change in late life," International Journal of Obesity, vol. 37, no. 2, pp. 296-302, 2013.

[33] J. J. Virta, K. Heikkilä, M. Perola et al., "Midlife cardiovascular risk factors and late cognitive impairment," European Journal of Epidemiology, vol. 28, no. 5, pp. 405-416, 2013.

[34] S. Debette, S. Seshadri, A. Beiser et al., "Midlife vascular risk factor exposure accelerates structural brain aging and cognitive decline," Neurology, vol. 77, no. 5, pp. 461-468, 2011.

[35] J. A. Luchsinger, M. L. Biggs, J. R. Kizer et al., "Adiposity and cognitive decline in the cardiovascular health study," Neuroepidemiology, vol. 40, no. 4, pp. 274-281, 2013.

[36] D. Gustafson, "A life course of adiposity and dementia," European Journal of Pharmacology, vol. 585, no. 1, pp. 163-175, 2008.

[37] D. R. Gustafson, "Adiposity and cognitive decline: underlying mechanisms," Journal of Alzheimer's Disease, vol. 30, no. 2, pp. S97-S112, 2012.

[38] S. García-Ptacek, G. Faxén-Irving, P. Čermáková, M. Eriksdotter, and D. Religa, "Body mass index in dementia," European Journal of Clinical Nutrition, vol. 68, no. 11, pp. 1204-1209, 2014.

[39] A. Singh-Manoux, S. Czernichow, A. Elbaz et al., "Obesity phenotypes in midlife and cognition in early old age: the Whitehall II cohort study," Neurology, vol. 79, no. 8, pp. 755-762, 2012.
[40] A.-M. Tolppanen, T. Ngandu, I. Kåreholt et al., "Midlife and late-life body mass index and late-life dementia: results from a prospective population-based cohort," Journal of Alzheimer's Disease, vol. 38, no. 1, pp. 201-209, 2014.

[41] S. Gazdzinski, J. Kornak, M. W. Weiner, D. J. Meyerhoff, and R. Nat, "Body mass index and magnetic resonance markers of brain integrity in adults," Annals of Neurology, vol. 63, no. 5, pp. 652-657, 2008.

[42] L. B. Hassing, A. K. Dahl, N. L. Pedersen, and B. Johansson, "Overweight in midlife is related to lower cognitive function 30 years later: a prospective study with longitudinal assessments," Dementia and Geriatric Cognitive Disorders, vol. 29, no. 6, pp. 543-552, 2010.

[43] J. Liang, B. E. Matheson, W. H. Kaye, and K. N. Boutelle, "Neurocognitive correlates of obesity and obesity-related behaviors in children and adolescents," International Journal of Obesity, vol. 38, no. 4, pp. 494-506, 2014.

[44] M. Slining, L. S. Adair, B. D. Goldman, J. B. Borja, and M. Bentley, "Infant overweight is associated with delayed motor development," Journal of Pediatrics, vol. 157, no. 1, pp. 20.e125.e1, 2010 .

[45] J. E. Southall, A. D. Okely, and J. R. Steele, "Actual and perceived physical competence in overweight and nonoverweight children," Pediatric Exercise Science, vol. 16, no. 1, pp. 15-24, 2004.

[46] A. A. Poulsen, L. Desha, J. Ziviani et al., "Fundamental movement skills and self-concept of children who are overweight," International Journal of Pediatric Obesity, vol. 6, no. 2, pp. E464E471, 2011.

[47] D. Roberts, D. Veneri, R. Decker, and M. Gannotti, "Weight status and gross motor skill in kindergarten children," Pediatric Physical Therapy, vol. 24, no. 4, pp. 353-360, 2012.

[48] J. M. Mond, H. Stich, P. J. Hay, A. Kraemer, and B. T. Baune, "Associations between obesity and developmental functioning in pre-school children: a population-based study," International Journal of Obesity, vol. 31, no. 7, pp. 1068-1073, 2007.

[49] H. Krombholz, "Motor and cognitive performance of overweight preschool children," Perceptual and Motor Skills, vol. 116, no. 1, pp. 40-57, 2013.

[50] I. Gentier, E. D'Hondt, S. Shultz et al., "Fine and gross motor skills differ between healthy-weight and obese children," Research in Developmental Disabilities, vol. 34, no. 11, pp. 40434051, 2013.

[51] J. Cawley and C. K. Spiess, "Obesity and skill attainment in early childhood," Economics and Human Biology, vol. 6, no. 3, pp. 388-397, 2008.

[52] M. L. Vanden Bosch, L. B. Robbins, K. A. Pfeiffer, A. S. Kazanis, and K. S. Maier, "Demographic, cognitive, affective, and behavioral variables associated with overweight and obesity in low-active girls," Journal of Pediatric Nursing, vol. 29, no. 6, pp. 576-585, 2014.

[53] E. S. Bryant, M. J. Duncan, and S. L. Birch, "Fundamental movement skills and weight status in British primary school children," European Journal of Sport Science, vol. 14, no. 7, pp. 730-736, 2014.

[54] D. P. Cliff, A. D. Okely, P. J. Morgan, R. A. Jones, J. R. Steele, and L. A. Baur, "Proficiency deficiency: mastery of fundamental movement skills and skill components in overweight and obese children," Obesity, vol. 20, no. 5, pp. 1024-1033, 2012.

[55] A. D. Okely, M. L. Booth, and T. Chey, "Relationships between body composition and fundamental movement skills among children and adolescents," Research Quarterly for Exercise and Sport, vol. 75, no. 3, pp. 238-247, 2004. 
[56] C. Kemp and A. E. Pienaar, "Relationship between the body composition and motor and physical competence of Grade 1 learners in South Africa," Journal of Sports Medicine and Physical Fitness, vol. 53, no. 6, pp. 635-643, 2013.

[57] E. D'Hondt, V. Segers, B. Deforche et al., "The role of vision in obese and normal-weight children's gait control," Gait and Posture, vol. 33, no. 2, pp. 179-184, 2011.

[58] E. D’Hondt, B. Deforche, I. De Bourdeaudhuij, and M. Lenoir, "Childhood obesity affects fine motor skill performance under different postural constraints," Neuroscience Letters, vol. 440, no. 1, pp. 72-75, 2008.

[59] A. Z. Moore, G. Caturegli, E. J. Metter et al., "Difference in muscle quality over the adult life span and biological correlates in the baltimore longitudinal study of aging," Journal of the American Geriatrics Society, vol. 62, no. 2, pp. 230-236, 2014.

[60] R. K. Mehta and A. E. Shortz, "Obesity-related differences in neural correlates of force control," European Journal of Applied Physiology, vol. 114, no. 1, pp. 197-204, 2014.

[61] R. M. Malina, G. P. Beunen, A. L. Classens et al., "Fatness and physical-fitness of girls 7 to 17 years," Obesity Research, vol. 3, no. 3, pp. 221-231, 1995.

[62] M. L. Ponta, M. Gozza, J. Giacinto, R. Gradaschi, and G. F. Adami, "Effects of obesity on posture and walking: study prior to and following surgically induced weight loss," Obesity Surgery, vol. 24, no. 11, pp. 1915-1920, 2014.

[63] S. R. Waldstein and L. I. Katzel, "Interactive relations of central versus total obesity and blood pressure to cognitive function," International Journal of Obesity, vol. 30, no. 1, pp. 201-207, 2006.

[64] J.-B. Mignardot, I. Olivier, E. Promayon, and V. Nougier, "Obesity impact on the attentional cost for controlling posture," PLoS ONE, vol. 5, no. 12, Article ID e14387, 2010.

[65] J. C. D. Nguyen, A. S. Killcross, and T. A. Jenkins, "Obesity and cognitive decline: role of inflammation and vascular changes," Frontiers in Neuroscience, vol. 8, article 375, 2014.

[66] I. A. C. Arnoldussen, A. J. Kiliaan, and D. R. Gustafson, "Obesity and dementia: adipokines interact with the brain," European Neuropsychopharmacology, vol. 24, no. 12, pp. 1982-1999, 2014.

[67] M. M. Gonzales, T. Tarumi, D. E. Eagan, H. Tanaka, M. Vaghasia, and A. P. Haley, "Indirect effects of elevated body mass index on memory performance through altered cerebral metabolite concentrations," Psychosomatic Medicine, vol. 74, no. 7, pp. 691-698, 2012.

[68] L. R. Freeman, V. Haley-Zitlin, D. S. Rosenberger, and A.-C. Granholm, "Damaging effects of a high-fat diet to the brain and cognition: a review of proposed mechanisms," Nutritional Neuroscience, vol. 17, no. 6, pp. 241-251, 2014.

[69] C. E. Greenwood and G. Winocur, "High-fat diets, insulin resistance and declining cognitive function," Neurobiology of Aging, vol. 26, no. 1, supplement, pp. S42-S45, 2005.

[70] J. S. Y. Chan, J. H. Yan, and V. G. Payne, "The impact of obesity and exercise on cognitive aging," Frontiers in Aging Neuroscience, vol. 5, article 97, 2013.

[71] V. Frisardi, V. Solfrizzi, D. Seripa et al., "Metabolic-cognitive syndrome: a cross-talk between metabolic syndrome and Alzheimer's disease," Ageing Research Reviews, vol. 9, no. 4, pp. 399-417, 2010.

[72] A. J. Bruce-Keller, J. N. Keller, and C. D. Morrison, "Obesity and vulnerability of the CNS," Biochimica et Biophysica ActaMolecular Basis of Disease, vol. 1792, no. 5, pp. 395-400, 2009.

[73] I. Marqués-Iturria, R. Pueyo, M. Garolera et al., "Frontal cortical thinning and subcortical volume reductions in early adulthood obesity," Psychiatry Research-Neuroimaging, vol. 214, no. 2, pp. 109-115, 2013.

[74] K. Mueller, J. Sacher, K. Arelin et al., "Overweight and obesity are associated with neuronal injury in the human cerebellum and hippocampus in young adults: a combined MRI, serum marker and gene expression study," Translational Psychiatry, vol. 2, article e200, 2012.

[75] M. E. Walton, T. E. J. Behrens, M. J. Buckley, P. H. Rudebeck, and M. F. S. Rushworth, "Separable learning systems in the macaque brain and the role of orbitofrontal cortex in contingent learning," Neuron, vol. 65, no. 6, pp. 927-939, 2010.

[76] L. R. Squire, "Memory and the hippocampus-a synthesis from findings with rats, monkeys, and humans," Psychological Review, vol. 99, no. 2, pp. 195-231, 1992.

[77] K. Doya, "Complementary roles of basal ganglia and cerebellum in learning and motor control," Current Opinion in Neurobiology, vol. 10, no. 6, pp. 732-739, 2000.

[78] C. L. White, P. J. Pistell, M. N. Purpera et al., "Effects of high fat diet on Morris maze performance, oxidative stress, and inflammation in rats: contributions of maternal diet," Neurobiology of Disease, vol. 35, no. 1, pp. 3-13, 2009.

[79] C. D. Morrison, P. J. Pistell, D. K. Ingram et al., "High fat diet increases hippocampal oxidative stress and cognitive impairment in aged mice: implications for decreased Nrf2 signaling," Journal of Neurochemistry, vol. 114, no. 6, pp. 1581-1589, 2010.

[80] L. R. Freeman, L. Zhang, A. Nair et al., "Obesity increases cerebrocortical reactive oxygen species and impairs brain function," Free Radical Biology and Medicine, vol. 56, pp. 226-233, 2013.

[81] C. L. Baym, N. A. Khan, J. M. Monti et al., "Dietary lipids are differentially associated with hippocampal-dependent relational memory in prepubescent children," American Journal of Clinical Nutrition, vol. 99, no. 5, pp. 1026-1033, 2014.

[82] J. Wang, D. Freire, L. Knable et al., "Childhood and adolescent obesity and long-term cognitive consequences during aging," Journal of Comparative Neurology, vol. 523, no. 5, pp. 757-768, 2015.

[83] M. O. Dietrich, A. Muller, M. Bolos et al., "Western style diet impairs entrance of blood-borne insulin-like growth factor-1 into the brain," NeuroMolecular Medicine, vol. 9, no. 4, pp. 324330, 2007.

[84] S. A. Farr, K. A. Yamada, D. A. Butterfield et al., "Obesity and hypertriglyceridemia produce cognitive impairment," Endocrinology, vol. 149, no. 5, pp. 2628-2636, 2008.

[85] W. A. Banks, A. B. Coon, S. M. Robinson et al., "Triglycerides induce leptin resistance at the blood-brain barrier," Diabetes, vol. 53, no. 5, pp. 1253-1260, 2004.

[86] C. Boitard, A. Cavaroc, J. Sauvant et al., "Impairment of hippocampal-dependent memory induced by juvenile high-fat diet intake is associated with enhanced hippocampal inflammation in rats," Brain, Behavior, and Immunity, vol. 40, pp. 9-17, 2014.

[87] T. M. Hsu and S. E. Kanoski, "Blood-brain barrier disruption: mechanistic links between western diet consumption and dementia," Frontiers in Aging Neuroscience, vol. 6, article 88, 2014.

[88] S. E. Arnold, I. Lucki, B. R. Brookshire et al., "High fat diet produces brain insulin resistance, synaptodendritic abnormalities and altered behavior in mice," Neurobiology of Disease, vol. 67, pp. 79-87, 2014.

[89] R. Coppari and C. Bjørbæk, "Leptin revisited: its mechanism of action and potential for treating diabetes," Nature Reviews Drug Discovery, vol. 11, no. 9, pp. 692-708, 2012. 
[90] H. Feng, L. Zheng, Z. Feng, Y. Zhao, and N. Zhang, "The role of leptin in obesity and the potential for leptin replacement therapy," Endocrine, vol. 44, no. 1, pp. 33-39, 2013.

[91] S. Lehr, S. Hartwig, and H. Sell, "Adipokines: a treasure trove for the discovery of biomarkers for metabolic disorders," Proteomics-Clinical Applications, vol. 6, no. 1-2, pp. 91-101, 2012.

[92] O. M. Farr, M. A. Tsoukas, and C. S. Mantzoros, "Leptin and the brain: influences on brain development, cognitive functioning and psychiatric disorders," Metabolism: Clinical and Experimental, vol. 64, no. 1, pp. 114-130, 2015.

[93] A. M. Stranahan, T. V. Arumugam, R. G. Cutler, K. Lee, J. M. Egan, and M. P. Mattson, "Diabetes impairs hippocampal function through glucocorticoid-mediated effects on new and mature neurons," Nature Neuroscience, vol. 11, no. 3, pp. 309317, 2008.

[94] A.-L. Dinel, C. André, A. Aubert, G. Ferreira, S. Layé, and N. Castanon, "Cognitive and emotional alterations are related to hippocampal inflammation in a mouse model of metabolic syndrome," PLoS ONE, vol. 6, no. 9, Article ID e24325, 2011.

[95] J. R. Erion, M. Wosiski-Kuhn, A. Dey et al., "Obesity elicits interleukin 1-mediated deficits in hippocampal synaptic plasticity," The Journal of Neuroscience, vol. 34, no. 7, pp. 2618-2631, 2014.

[96] S. G. Bouret, "Neurodevelopmental actions of leptin," Brain Research, vol. 1350, pp. 2-9, 2010.

[97] Y. Oomura, N. Hori, T. Shiraishi et al., "Leptin facilitates learning and memory performance and enhances hippocampal CA1 long-term potentiation and CaMK II phosphorylation in rats," Peptides, vol. 27, no. 11, pp. 2738-2749, 2006.

[98] L. J. Shanley, A. J. Irving, and J. Harvey, "Leptin enhances NMDA receptor function and modulates hippocampal synaptic plasticity," The Journal of Neuroscience, vol. 21, no. 24, Article ID RC186, 2001.

[99] C. A. Grillo, G. G. Piroli, L. Junor et al., "Obesity/hyperleptinemic phenotype impairs structural and functional plasticity in the rat hippocampus," Physiology and Behavior, vol. 105, no. 1, pp. 138-144, 2011.

[100] C. A. Grillo, G. G. Piroli, A. N. Evans et al., "Obesity/hyperleptinemic phenotype adversely affects hippocampal plasticity: effects of dietary restriction," Physiology and Behavior, vol. 104, no. 2, pp. 235-241, 2011.

[101] K. F. Holden, K. Lindquist, F. A. Tylavsky, C. Rosano, T. B. Harris, and K. Yaffe, "Serum leptin level and cognition in the elderly: findings from the Health ABC Study," Neurobiology of Aging, vol. 30, no. 9, pp. 1483-1489, 2009.

[102] A. Zeki Al Hazzouri, M. N. Haan, R. A. Whitmer, K. Yaffe, and J. Neuhaus, "Central obesity, leptin and cognitive decline: the sacramento area Latino study on aging," Dementia and Geriatric Cognitive Disorders, vol. 33, no. 6, pp. 400-409, 2012.

[103] J. Folch, I. Pedrós, I. Patraca et al., "Neuroprotective and antiageing role of leptin," Journal of Molecular Endocrinology, vol. 49, no. 3, pp. R149-R156, 2012.

[104] W. Lieb, A. S. Beiser, R. S. Vasan et al., "Association of plasma leptin levels with incident Alzheimer disease and MRI measures of brain aging," The Journal of the American Medical Association, vol. 302, no. 23, pp. 2565-2572, 2009.

[105] M. Mapfei, J. Halaas, E. Ravussin et al., "Leptin levels in human and rodent: measurement of plasma leptin and ob RNA in obese and weight-reduced subjects," Nature Medicine, vol. 1, no. 11, pp. 1155-1161, 1995.
[106] N. Castanon, G. Luheshi, and S. Layé, "Role of neuroinflammation in the emotional and cognitive alterations displayed by animal models of obesity," Frontiers in Neuroscience, vol. 9, article 229, 2015.

[107] P. R. Moult and J. Harvey, "Hormonal regulation of hippocampal dendritic morphology and synaptic plasticity," Cell Adhesion \& Migration, vol. 2, no. 4, pp. 269-275, 2008.

[108] J. W. Unger, J. N. Livingston, and A. M. Moss, "Insulin receptors in the central nervous system: localization, signalling mechanisms and functional aspects," Progress in Neurobiology, vol. 36, no. 5, pp. 343-362, 1991.

[109] C. Maffeis, R. Manfredi, M. Trombetta et al., "Insulin sensitivity is correlated with subcutaneous but not visceral body fat in overweight and obese prepubertal children," Journal of Clinical Endocrinology and Metabolism, vol. 93, no. 6, pp. 2122-2128, 2008.

[110] D. P. Figlewicz, J. L. Bennett, A. M. Naleid, C. Davis, and J. W. Grimm, "Intraventricular insulin and leptin decrease sucrose self-administration in rats," Physiology and Behavior, vol. 89, no. 4, pp. 611-616, 2006.

[111] M. Qatanani and M. A. Lazar, "Mechanisms of obesityassociated insulin resistance: many choices on the menu," Genes and Development, vol. 21, no. 12, pp. 1443-1455, 2007.

[112] B. Cholerton, L. D. Baker, and S. Craft, "Insulin resistance and pathological brain ageing," Diabetic Medicine, vol. 28, no. 12, pp. 1463-1475, 2011.

[113] B. Kim and E. L. Feldman, "Insulin resistance as a key link for the increased risk of cognitive impairment in the metabolic syndrome," Experimental \& Molecular Medicine, vol. 47, no. 3, article e149, 2015.

[114] C. Messier and K. Teutenberg, "The role of insulin, insulin growth factor, and insulin-degrading enzyme in brain aging and Alzheimer's disease," Neural Plasticity, vol. 12, no. 4, pp. 311-328, 2005.

[115] S. M. de la Monte, "Insulin resistance and Alzheimer's disease," BMB Reports, vol. 42, no. 8, pp. 475-481, 2009.

[116] A. Kleinridders, H. A. Ferris, W. K. Cai, and C. R. Kahn, "Insulin action in brain regulates systemic metabolism and brain function," Diabetes, vol. 63, no. 7, pp. 2232-2243, 2014.

[117] S. Craft, "Insulin resistance syndrome and Alzheimer's disease: age- and obesity-related effects on memory, amyloid, and inflammation," Neurobiology of Aging, vol. 26, supplement, no. 1, pp. S65-S69, 2005.

[118] G. S. Watson and S. Craft, "The role of insulin resistance in the pathogenesis of Alzheimer's disease: implications for treatment," CNS Drugs, vol. 17, no. 1, pp. 27-45, 2003.

[119] L. Letra, I. Santana, and R. Seiça, "Obesity as a risk factor for Alzheimer's disease: the role of adipocytokines," Metabolic Brain Disease, vol. 29, no. 3, pp. 563-568, 2014.

[120] J. Nedvídková, K. Smitka, V. Kopský, and V. Hainer, "Adiponectin, an adipocyte-derived protein," Physiological Research, vol. 54, no. 2, pp. 133-140, 2005.

[121] T. Pancani, K. L. Anderson, L. D. Brewer et al., "Effect of high-fat diet on metabolic indices, cognition, and neuronal physiology in aging F344 rats," Neurobiology of Aging, vol. 34, no. 8, pp. 1977-1987, 2013.

[122] E. Carro, J. L. Trejo, T. Gomez-Isla, D. LeRoith, and I. TorresAleman, "Serum insulin-like growth factor I regulates brain amyloid- $\beta$ levels," Nature Medicine, vol. 8, no. 12, pp. 1390-1397, 2002. 
[123] L. J. Spielman, J. P. Little, and A. Klegeris, "Inflammation and insulin/IGF-1 resistance as the possible link between obesity and neurodegeneration," Journal of Neuroimmunology, vol. 273, no. 1-2, pp. 8-21, 2014.

[124] E. J. Huang and L. F. Reichardt, "Neurotrophins: roles in neuronal development and function," Annual Review of Neuroscience, vol. 24, pp. 677-736, 2001.

[125] A. Patapoutian and L. F. Reichardt, "Trk receptors: mediators of neurotrophin action," Current Opinion in Neurobiology, vol. 11, no. 3, pp. 272-280, 2001.

[126] G. D. Yancopoulos and R. M. Lindsay, "A BDNF autocrine loop in adult sensory neurons prevents cell death," Nature, vol. 374, no. 6521, pp. 450-453, 1995.

[127] G. N. Chaldakov, A. B. Tonchev, and L. Aloe, "NGF and BDNF: from nerves to adipose tissue, from neurokines to metabokines," Rivista di Psichiatria, vol. 44, no. 2, pp. 79-87, 2009.

[128] E. E. Noble, C. J. Billington, C. M. Kotz, and C. F. Wang, "The lighter side of BDNF," American Journal of PhysiologyRegulatory Integrative and Comparative Physiology, vol. 300, no. 5, pp. R1053-R1069, 2011.

[129] H. R. Park, M. Park, J. Choi, K.-Y. Park, H. Y. Chung, and J. Lee, "A high-fat diet impairs neurogenesis: involvement of lipid peroxidation and brain-derived neurotrophic factor," Neuroscience Letters, vol. 482, no. 3, pp. 235-239, 2010.

[130] A. M. Stranahan, E. D. Norman, K. Lee et al., "Diet-induced insulin resistance impairs hippocampal synaptic plasticity and cognition in middle-aged rats," Hippocampus, vol. 18, no. 11, pp. 1085-1088, 2008.

[131] K. M. Baumgarner, S. Setti, C. Diaz, A. Littlefield, A. Jones, and R. A. Kohman, "Diet-induced obesity attenuates cytokine production following an immune challenge," Behavioural Brain Research, vol. 267, pp. 33-41, 2014.

[132] P. J. Turnbaugh and J. I. Gordon, "The core gut microbiome, energy balance and obesity," The Journal of Physiology, vol. 587, no. 17, pp. 4153-4158, 2009.

[133] J. F. Cryan and T. G. Dinan, "Mind-altering microorganisms: the impact of the gut microbiota on brain and behaviour," Nature Reviews Neuroscience, vol. 13, no. 10, pp. 701-712, 2012.

[134] V. Tremaroli and F. Bäckhed, "Functional interactions between the gut microbiota and host metabolism," Nature, vol. 489, no. 7415, pp. 242-249, 2012.

[135] B. M. Corfe, C. J. Harden, M. Bull, and I. Garaiova, "The multifactorial interplay of diet, the microbiome and appetite control: current knowledge and future challenges," Proceedings of the Nutrition Society, vol. 74, no. 3, pp. 235-244, 2015.

[136] J. K. Nicholson, E. Holmes, J. Kinross et al., "Host-gut microbiota metabolic interactions," Science, vol. 336, no. 6086, pp. 1262-1267, 2012.

[137] C. L. J. Karlsson, J. Önnerfält, J. Xu, G. Molin, S. Ahrné, and K. Thorngren-Jerneck, "The microbiota of the gut in preschool children with normal and excessive body weight," Obesity, vol. 20, no. 11, pp. 2257-2261, 2012.

[138] M. Manco, "Gut microbiota and developmental programming of the brain: from evidence in behavioral endophenotypes to novel perspective in obesity," Frontiers in Cellular and Infection Microbiology, vol. 2, article 109, 2012.

[139] F. Bäckhed, J. K. Manchester, C. F. Semenkovich, and J. I. Gordon, "Mechanisms underlying the resistance to diet-induced obesity in germ-free mice," Proceedings of the National Academy of Sciences of the United States of America, vol. 104, no. 3, pp. 979-984, 2007.
[140] F. Bäckhed, H. Ding, T. Wang et al., "The gut microbiota as an environmental factor that regulates fat storage," Proceedings of the National Academy of Sciences of the United States of America, vol. 101, no. 44, pp. 15718-15723, 2004.

[141] R. E. Ley, F. Bäckhed, P. Turnbaugh, C. A. Lozupone, R. D. Knight, and J. I. Gordon, "Obesity alters gut microbial ecology," Proceedings of the National Academy of Sciences of the United States of America, vol. 102, no. 31, pp. 11070-11075, 2005.

[142] P. J. Turnbaugh, R. E. Ley, M. A. Mahowald, V. Magrini, E. R. Mardis, and J. I. Gordon, "An obesity-associated gut microbiome with increased capacity for energy harvest," Nature, vol. 444, no. 7122, pp. 1027-1031, 2006.

[143] R. A. Luna and J. A. Foster, "Gut brain axis: diet microbiota interactions and implications for modulation of anxiety and depression," Current Opinion in Biotechnology, vol. 32, pp. 3541, 2015.

[144] R. D. Moloney, L. Desbonnet, G. Clarke, T. G. Dinan, and J. F. Cryan, "The microbiome: stress, health and disease," Mammalian Genome, vol. 25, no. 1-2, pp. 49-74, 2014.

[145] A. J. Bruce-Keller, J. M. Salbaum, M. Luo et al., "Obese-type gut microbiota induce neurobehavioral changes in the absence of obesity," Biological Psychiatry, vol. 77, no. 7, pp. 607-615, 2014.

[146] C. P. Moran and F. Shanahan, "Gut microbiota and obesity: role in aetiology and potential therapeutic target," Best Practice \& Research Clinical Gastroenterology, vol. 28, no. 4, pp. 585-597, 2014.

[147] K. R. Magnusson, L. Hauck, B. M. Jeffrey et al., "Relationships between diet-related changes in the gut microbiome and cognitive flexibility," Neuroscience, vol. 300, pp. 128-140, 2015.

[148] J. Fernandes, W. Su, S. Rahat-Rozenbloom, T. M. S. Wolever, and E. M. Comelli, "Adiposity, gut microbiota and faecal short chain fatty acids are linked in adult humans," Nutrition and Diabetes, vol. 4, article e121, 2014.

[149] R. D. Heijtz, S. Wang, F. Anuar et al., "Normal gut microbiota modulates brain development and behavior," Proceedings of the National Academy of Sciences of the United States of America, vol. 108, no. 7, pp. 3047-3052, 2011.

[150] M. Douglas-Escobar, E. Elliott, and J. Neu, "Effect of intestinal microbial ecology on the developing brain," JAMA Pediatrics, vol. 167, no. 4, pp. 374-379, 2013.

[151] N. Napoli, K. Shah, D. L. Waters, D. R. Sinacore, C. Qualls, and D. T. Villareal, "Effect of weight loss, exercise, or both on cognition and quality of life in obese older adults," The American Journal of Clinical Nutrition, vol. 100, no. 1, pp. 189-198, 2014.

[152] K. I. Erickson, L. Oberlin, S. Gujral et al., "Exercise as a way of capitalizing on neuroplasticity in late adulthood," Topics in Geriatric Rehabilitation, vol. 30, no. 1, pp. 8-14, 2014.

[153] J. D. Churchill, R. Galvez, S. Colcombe, R. A. Swain, A. F. Kramer, and W. T. Greenough, "Exercise, experience and the aging brain," Neurobiology of Aging, vol. 23, no. 5, pp. 941-955, 2002.

[154] S. B. Chapman, S. Aslan, J. S. Spence et al., "Shorter term aerobic exercise improves brain, cognition, and cardiovascular fitness in aging," Frontiers in Aging Neuroscience, vol. 5, article 75, 2013.

[155] T. K. Bhattacharya, B. D. Pence, J. M. Ossyra, T. E. Gibbons, S. Perez, R. H. McCusker et al., "Exercise but not (-)-Epigallocatechin-3-gallate or $\beta$-Alanine enhances physical fitness, brain plasticity, and behavioral performance in mice," Physiology \& Behavior, vol. 145, pp. 29-37, 2015.

[156] S. J. Colcombe, A. F. Kramer, K. I. Erickson et al., "Cardiovascular fitness, cortical plasticity, and aging," Proceedings of the 
National Academy of Sciences of the United States of America, vol. 101, no. 9, pp. 3316-3321, 2004.

[157] K. I. Erickson, R. S. Prakash, M. W. Voss et al., "Aerobic fitness is associated with hippocampal volume in elderly humans," Hippocampus, vol. 19, no. 10, pp. 1030-1039, 2009.

[158] G. Zhao, H. L. Liu, H. Zhang, and X. J. Tong, “Treadmill exercise enhances synaptic plasticity, but does not alter $\beta$ amyloid deposition in hippocampi of aged APP/PS1 transgenic mice," Neuroscience, vol. 298, pp. 357-366, 2015.

[159] C. Niemann, B. Godde, and C. Voelcker-Rehage, "Not only cardiovascular, but also coordinative exercise increases hippocampal volume in older adults," Frontiers in Aging Neuroscience, vol. 6, article 170, 2014.

[160] T. Kobilo, Q.-R. Liu, K. Gandhi, M. Mughal, Y. Shaham, and $\mathrm{H}$. van Praag, "Running is the neurogenic and neurotrophic stimulus in environmental enrichment," Learning \& Memory, vol. 18, no. 9, pp. 605-609, 2011.

[161] K. I. Erickson, M. W. Voss, R. S. Prakash et al., "Exercise training increases size of hippocampus and improves memory," Proceedings of the National Academy of Sciences of the United States of America, vol. 108, no. 7, pp. 3017-3022, 2011.

[162] F. G. de Melo Coelho, T. M. Vital, A. M. Stein et al., "Acute aerobic exercise increases brain-derived neurotrophic factor levels in elderly with Alzheimer's disease," Journal of Alzheimer's Disease, vol. 39, no. 2, pp. 401-408, 2014.

[163] L. F. Ten Brinke, N. Bolandzadeh, L. S. Nagamatsu et al., "Aerobic exercise increases hippocampal volume in older women with probable mild cognitive impairment: a 6-month randomised controlled trial," British Journal of Sports Medicine, vol. 49, no. 4, pp. 248-254, 2015.

[164] K. Inoue, Y. Hanaoka, T. Nishijima et al., "Long-term mild exercise training enhances hippocampus-dependent memory in rats," International Journal of Sports Medicine, vol. 36, no. 4, pp. 280-285, 2015.

[165] B. M. Brown, J. J. Peiffer, and R. N. Martins, "Multiple effects of physical activity on molecular and cognitive signs of brain aging: can exercise slow neurodegeneration and delay Alzheimer's disease?" Molecular Psychiatry, vol. 18, no. 8, pp. 864-874, 2013.

[166] L. Chaddock, M. B. Pontifex, C. H. Hillman, and A. F. Kramer, "A review of the relation of aerobic fitness and physical activity to brain structure and function in children," Journal of the International Neuropsychological Society, vol. 17, no. 6, pp. 975985, 2011.

[167] D. A. Fleischman, J. Yang, K. Arfanakis et al., "Physical activity, motor function, and white matter hyperintensity burden in healthy older adults," Neurology, vol. 84, no. 13, pp. 1294-1300, 2015.

[168] K. Skriver, M. Roig, J. Lundbye-Jensen et al., "Acute exercise improves motor memory: exploring potential biomarkers," Neurobiology of Learning and Memory, vol. 116, pp. 46-58, 2014.

[169] B. Y. Tseng, T. Gundapuneedi, M. A. Khan et al., "White matter integrity in physically fit older adults," NeuroImage, vol. 82, pp. 510-516, 2013.

[170] J. M. Bugg, K. Shah, D. T. Villareal, and D. Head, "Cognitive and neural correlates of aerobic fitness in obese older adults," Experimental Aging Research, vol. 38, no. 2, pp. 131-145, 2012.

[171] T. M. Burkhalter and C. H. Hillman, "A narrative review of physical activity, nutrition, and obesity to cognition and scholastic performance across the human lifespan," Advances in Nutrition, vol. 2, no. 2, pp. 201S-206S, 2011.
[172] C. L. Davis, P. D. Tomporowski, C. A. Boyle et al., "Effects of aerobic exercise on overweight children's cognitive functioning: a randomized controlled trial," Research Quarterly for Exercise and Sport, vol. 78, no. 5, pp. 510-519, 2007.

[173] J. Drigny, V. Gremeaux, O. Dupuy et al., "Effect of interval training on cognitive functioning and cerebral oxygenation in obese patients: a pilot study," Journal of Rehabilitation Medicine, vol. 46, no. 10, pp. 1050-1054, 2014.

[174] A. A. de Almeida, S. G. da Silva, J. Fernandes et al., "Differential effects of exercise intensities in hippocampal BDNF, inflammatory cytokines and cell proliferation in rats during the postnatal brain development," Neuroscience Letters, vol. 553, pp. 1-6, 2013.

[175] K. I. Erickson and A. F. Kramer, "Aerobic exercise effects on cognitive and neural plasticity in older adults," British Journal of Sports Medicine, vol. 43, no. 1, pp. 22-24, 2009.

[176] K. I. Erickson, A. M. Weinstein, and O. L. Lopez, "Physical activity, brain plasticity, and Alzheimer's disease," Archives of Medical Research, vol. 43, no. 8, pp. 615-621, 2012.

[177] S.-J. Lou, J.-Y. Liu, H. Chang, and P.-J. Chen, "Hippocampal neurogenesis and gene expression depend on exercise intensity in juvenile rats," Brain Research, vol. 1210, pp. 48-55, 2008.

[178] L. T. Ferris, J. S. Williams, and C.-L. Shen, "The effect of acute exercise on serum brain-derived neurotrophic factor levels and cognitive function," Medicine and Science in Sports and Exercise, vol. 39, no. 4, pp. 728-734, 2007.

[179] F. G. D. M. Coelho, S. Gobbi, C. A. A. Andreatto, D. I. Corazza, R. V. Pedroso, and R. F. Santos-Galduróz, "Physical exercise modulates peripheral levels of Brain-Derived Neurotrophic Factor (BDNF): a systematic review of experimental studies in the elderly," Archives of Gerontology and Geriatrics, vol. 56, no. 1, pp. 10-15, 2013.

[180] P. D. Tomporowski, C. L. Davis, K. Lambourne, M. Gregoski, and J. Tkacz, "Task switching in overweight children: effects of acute exercise and age," Journal of Sport and Exercise Psychology, vol. 30, no. 5, pp. 497-511, 2008.

[181] S. Di Loreto, S. Falone, A. D’Alessandro et al., "Regular and moderate exercise initiated in middle age prevents age-related amyloidogenesis and preserves synaptic and neuroprotective signaling in mouse brain cortex," Experimental Gerontology, vol. 57, pp. 57-65, 2014.

[182] A. R. Patten, H. Sickmann, B. N. Hryciw et al., "Long-term exercise is needed to enhance synaptic plasticity in the hippocampus," Learning and Memory, vol. 20, no. 11, pp. 642-647, 2013.

[183] M. E. Hopkins, R. Nitecki, and D. J. Bucci, "Physical exercise during adolescence versus adulthood: differential effects on object recognition memory and brain-derived neurotrophic factor levels," Neuroscience, vol. 194, pp. 84-94, 2011.

[184] H. van Praag, B. R. Christie, T. J. Sejnowski, and F. H. Gage, "Running enhances neurogenesis, learning, and long-term potentiation in mice," Proceedings of the National Academy of Sciences of the United States of America, vol. 96, no. 23, pp. 13427-13431, 1999.

[185] A. M. Singh and W. R. Staines, "The effects of acute aerobic exercise on the primary motor cortex," Journal of Motor Behavior, vol. 47, no. 4, pp. 328-339, 2015.

[186] É. W. Griffin, S. Mullally, C. Foley, S. A. Warmington, S. M. O’Mara, and Á. M. Kelly, "Aerobic exercise improves hippocampal function and increases BDNF in the serum of young adult males," Physiology \& Behavior, vol. 104, no. 5, pp. 934-941, 2011.

[187] C.-A. Grégoire, D. Bonenfant, A. Le Nguyen, A. Aumont, and K. J. L. Fernandes, "Untangling the influences of voluntary 
running, environmental complexity, social housing and stress on adult hippocampal neurogenesis," PLoS ONE, vol. 9, no. 1, Article ID e86237, 2014.

[188] C. W. Cotman and N. C. Berchtold, "Exercise: a behavioral intervention to enhance brain health and plasticity," Trends in Neurosciences, vol. 25, no. 6, pp. 295-301, 2002.

[189] J. L. Abel and E. F. Rissman, "Running-induced epigenetic and gene expression changes in the adolescent brain," International Journal of Developmental Neuroscience, vol. 31, no. 6, pp. 383390, 2013.

[190] R. K. Dishman, H.-R. Berthoud, F. W. Booth et al., "Neurobiology of exercise," Obesity, vol. 14, no. 3, pp. 345-356, 2006.

[191] H. Pareja-Galeano, T. Brioche, F. Sanchis-Gomar et al., "Impact of exercise training on neuroplasticity-related growth factors in adolescents," Journal of Musculoskeletal \& Neuronal Interactions, vol. 13, no. 3, pp. 368-371, 2013.

[192] S.-E. Kim, I.-G. Ko, M.-S. Shin et al., "Treadmill exercise and wheel exercise enhance expressions of neutrophic factors in the hippocampus of lipopolysaccharide-injected rats," Neuroscience Letters, vol. 538, pp. 54-59, 2013.

[193] K. A. Intlekofer and C. W. Cotman, "Exercise counteracts declining hippocampal function in aging and Alzheimer's disease," Neurobiology of Disease, vol. 57, pp. 47-55, 2013.

[194] P. Babaei, K. Azali Alamdari, B. Soltani Tehrani, and A. Damirchi, "Effect of six weeks of endurance exercise and following detraining on serum brain derived neurotrophic factor and memory performance in middle aged males with metabolic syndrome," Journal of Sports Medicine and Physical Fitness, vol. 53, no. 4, pp. 437-443, 2013.

[195] K. L. Szuhany, M. Bugatti, and M. W. Otto, "A meta-analytic review of the effects of exercise on brain-derived neurotrophic factor," Journal of Psychiatric Research, vol. 60, pp. 56-64, 2015.

[196] J.-L. Yang, Y.-T. Lin, P.-C. Chuang, V. A. Bohr, and M. P. Mattson, "BDNF and exercise enhance neuronal DNA repair by stimulating CREB-mediated production of apurinic/apyrimidinic endonuclease 1," NeuroMolecular Medicine, vol. 16, no. 1, pp. 161-174, 2014.

[197] A. S. Aguiar Jr., A. A. Castro, E. L. Moreira et al., "Short bouts of mild-intensity physical exercise improve spatial learning and memory in aging rats: involvement of hippocampal plasticity via AKT, CREB and BDNF signaling," Mechanisms of Ageing and Development, vol. 132, no. 11-12, pp. 560-567, 2011.

[198] P. Ambrogini, D. Lattanzi, S. Ciuffoli, M. Betti, M. Fanelli, and R. Cuppini, "Physical exercise and environment exploration affect synaptogenesis in adult-generated neurons in the rat dentate gyrus: possible role of BDNF," Brain Research, vol. 1534, pp. 1-12, 2013.

[199] R. G. Bechara, R. Lyne, and Á. M. Kelly, "BDNF-stimulated intracellular signalling mechanisms underlie exercise-induced improvement in spatial memory in the male Wistar rat," Behavioural Brain Research, vol. 275, pp. 297-306, 2014.

[200] Q. Ding, Z. Ying, and F. Gómez-Pinilla, "Exercise influences hippocampal plasticity by modulating brain-derived neurotrophic factor processing," Neuroscience, vol. 192, pp. 773-780, 2011.

[201] S. Bayod, J. Del Valle, A. M. Canudas et al., "Long-term treadmill exercise induces neuroprotective molecular changes in rat brain," Journal of Applied Physiology, vol. 111, no. 5, pp. 1380-1390, 2011.

[202] W. D. S. Killgore, E. A. Olson, and M. Weber, "Physical exercise habits correlate with gray matter volume of the hippocampus in healthy adult humans," Scientific Reports, vol. 3, article 3457, 2013.

[203] A. Sumiyoshi, Y. Taki, H. Nonaka, H. Takeuchi, and R. Kawashima, "Regional gray matter volume increases following 7 days of voluntary wheel running exercise: a longitudinal VBM study in rats," NeuroImage, vol. 98, pp. 82-90, 2014.

[204] K. L. McFadden, M.-A. Cornier, E. L. Melanson, J. L. Bechtell, and J. R. Tregellas, "Effects of exercise on resting-state default mode and salience network activity in overweight/obese adults," NeuroReport, vol. 24, no. 15, pp. 866-871, 2013.

[205] M. W. Voss, R. S. Prakash, K. I. Erickson et al., "Plasticity of brain networks in a randomized intervention trial of exercise training in older adults," Frontiers in Aging Neuroscience, vol. 2, article 32, 2010.

[206] K. Marosi, Z. Bori, N. Hart et al., "Long-term exercise treatment reduces oxidative stress in the hippocampus of aging rats," Neuroscience, vol. 226, pp. 21-28, 2012.

[207] S. G. da Silva, P. S. R. Simões, R. A. Mortara et al., "Exerciseinduced hippocampal anti-inflammatory response in aged rats," Journal of Neuroinflammation, vol. 10, article 61, 2013.

[208] C. W. Cotman, N. C. Berchtold, and L.-A. Christie, "Exercise builds brain health: key roles of growth factor cascades and inflammation," Trends in Neurosciences, vol. 30, no. 9, pp. 464472, 2007.

[209] C.-X. Huang, X. Qiu, S. Wang et al., "Exercise-induced changes of the capillaries in the cortex of middle-aged rats," Neuroscience, vol. 233, pp. 139-145, 2013.

[210] L. Saur, P. P. A. Baptista, P. N. de Senna et al., "Physical exercise increases GFAP expression and induces morphological changes in hippocampal astrocytes," Brain Structure and Function, vol. 219, no. 1, pp. 293-302, 2014.

[211] C. S. Latimer, J. L. Searcy, M. T. Bridges et al., "Reversal of glial and neurovascular markers of unhealthy brain aging by exercise in middle-aged female mice," PLoS ONE, vol. 6, no. 10, Article ID e26812, 2011.

[212] G. Paz-Filho, M.-L. Wong, and J. Licinio, “Ten years of leptin replacement therapy," Obesity Reviews, vol. 12, no. 501, pp. e315e323, 2011.

[213] K. Baicy, E. D. London, J. Monterosso et al., "Leptin replacement alters brain response to food cues in genetically leptin-deficient adults," Proceedings of the National Academy of Sciences of the United States of America, vol. 104, no. 46, pp. 18276-18279, 2007.

[214] J. A. Matochik, E. D. London, B. O. Yildiz et al., "Effect of leptin replacement on brain structure in genetically leptin-deficient adults," Journal of Clinical Endocrinology and Metabolism, vol. 90, no. 5, pp. 2851-2854, 2005.

[215] R. S. Ahima, "Revisiting leptin's role in obesity and weight loss," The Journal of Clinical Investigation, vol. 118, no. 7, pp. 23802383, 2008.

[216] S. M. de la Monte, L. Longato, M. Tong, and J. R. Wands, "Insulin resistance and neurodegeneration: roles of obesity, type 2 diabetes mellitus and non-alcoholic steatohepatitis," Current Opinion in Investigational Drugs, vol. 10, no. 10, pp. 1049-1060, 2009.

[217] J. Freiherr, M. Hallschmid, W. H. Frey II et al., "Intranasal insulin as a treatment for alzheimer's disease: a review of basic research and clinical evidence," CNS Drugs, vol. 27, no. 7, pp. 505-514, 2013.

[218] V. Ott, C. Benedict, B. Schultes, J. Born, and M. Hallschmid, "Intranasal administration of insulin to the brain impacts cognitive function and peripheral metabolism," Diabetes, Obesity and Metabolism, vol. 14, no. 3, pp. 214-221, 2012. 
[219] S. M. de La Monte, "Intranasal insulin therapy for cognitive impairment and neurodegeneration: current state of the art," Expert Opinion on Drug Delivery, vol. 10, no. 12, pp. 1699-1709, 2013.

[220] K. Jauch-Chara, A. Friedrich, M. Rezmer et al., "Intranasal insulin suppresses food intake via enhancement of brain energy levels in humans," Diabetes, vol. 61, no. 9, pp. 2261-2268, 2012.

[221] R. I. Henkin, "Intranasal insulin: from nose to brain," Nutrition, vol. 26, no. 6, pp. 624-633, 2010.

[222] J. Wilsey and P. J. Scarpace, "Caloric restriction reverses the deficits in leptin receptor protein and leptin signaling capacity associated with diet-induced obesity: role of leptin in the regulation of hypothalamic long-form leptin receptor expression," Journal of Endocrinology, vol. 181, no. 2, pp. 297-306, 2004.

[223] A. V. Araya, X. Orellana, and J. Espinoza, "Evaluation of the effect of caloric restriction on serum BDNF in overweight and obese subjects: preliminary evidences," Endocrine, vol. 33, no. 3, pp. 300-304, 2008.

[224] C. J. Boraxbekk, A. Stomby, M. Ryberg et al., "Diet-induced weight loss alters functional brain responses during an episodic memory task," Obesity Facts, vol. 8, no. 4, pp. 261-272, 2015. 

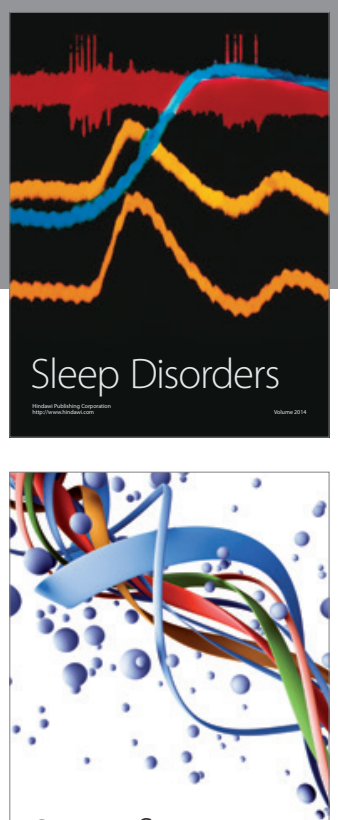

Scientifica
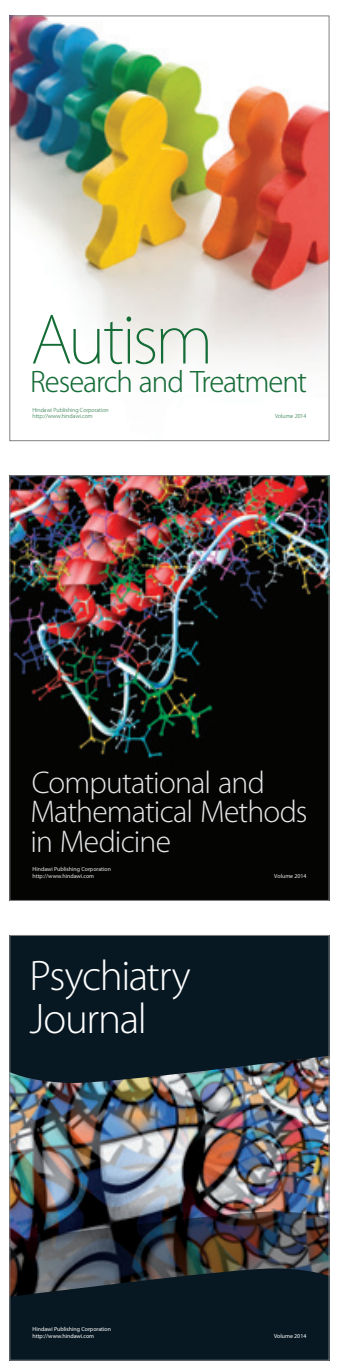
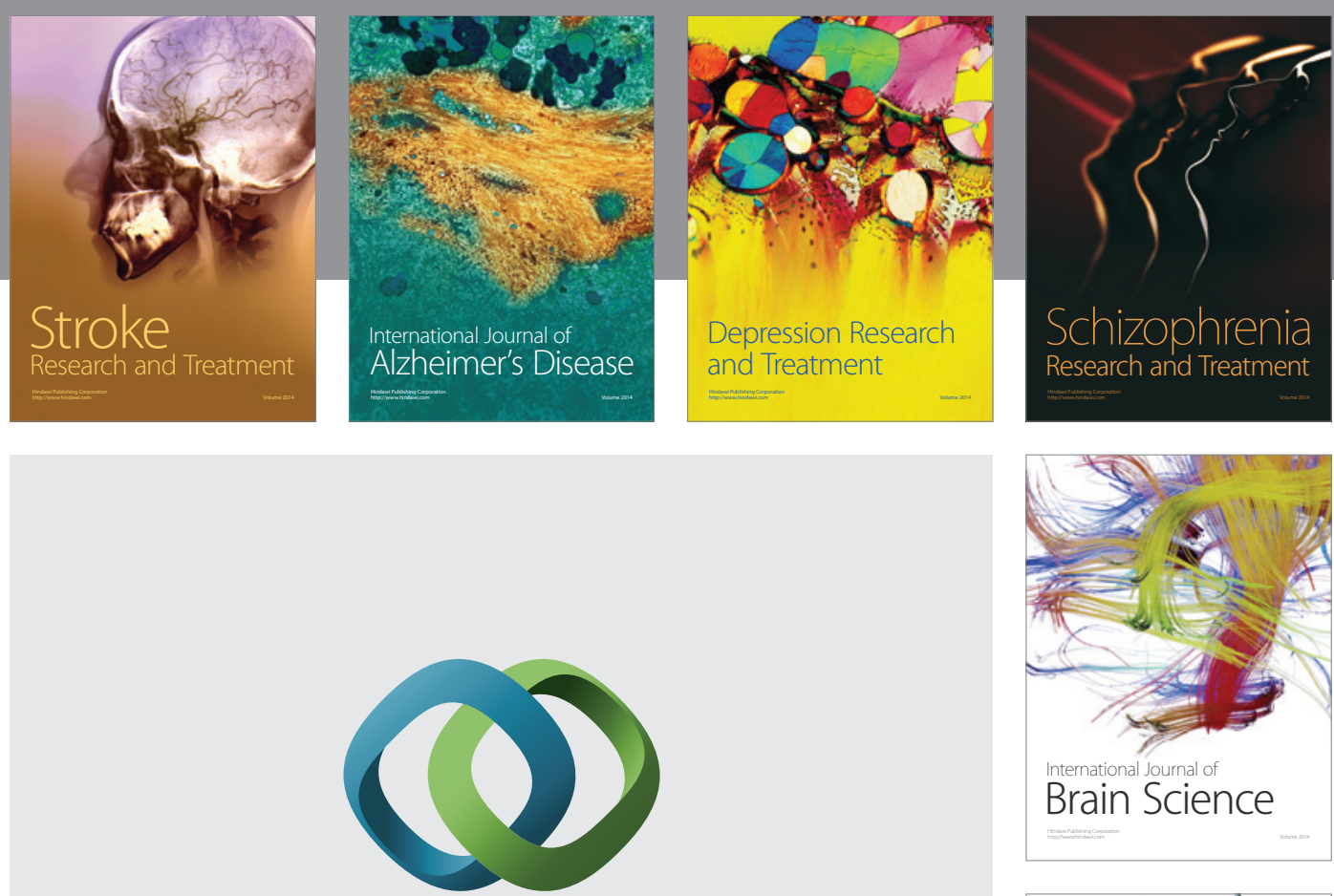

\section{Hindawi}

Submit your manuscripts at

http://www.hindawi.com
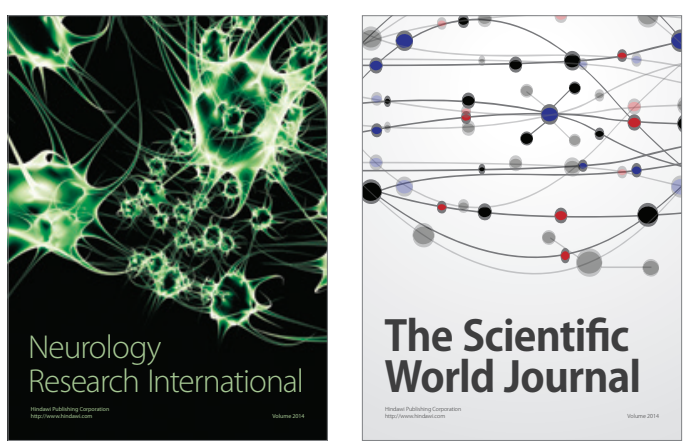

The Scientific World Journal

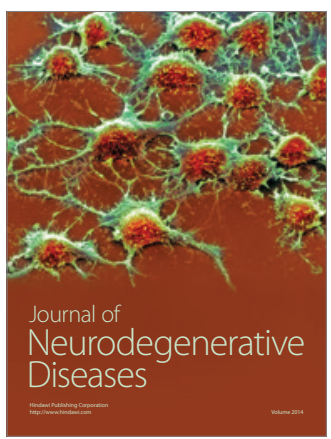

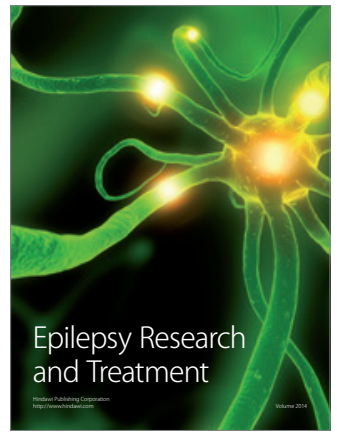

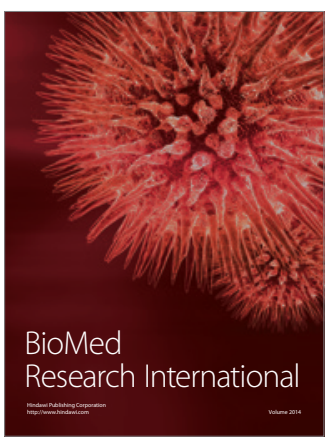

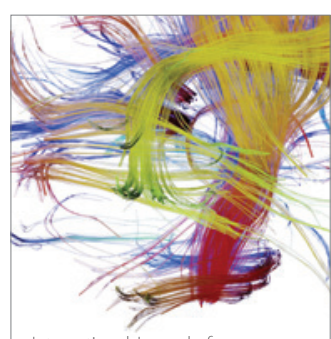

Brain Science

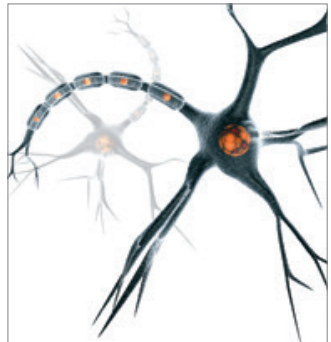

Neural Plasticity
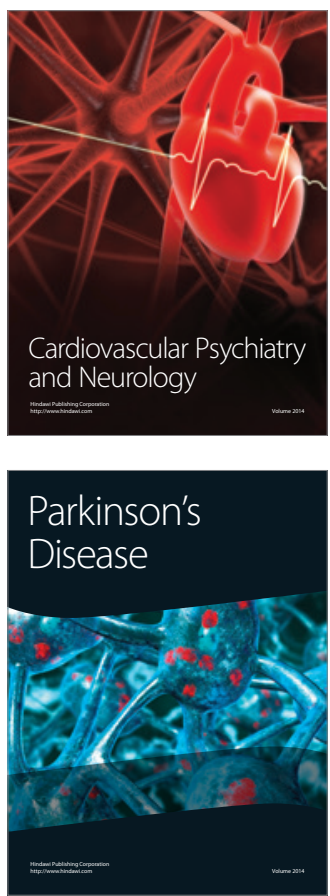